\title{
WI-FI Path Finding for Indoor Localization Using 802.11 Standards
}

\author{
${ }^{1}$ Sikandar Khan, ${ }^{2}$ Saeeda Usman and ${ }^{3}$ Adeel Akam \\ ${ }^{1}$ Comsats Institute of Information Technology \\ Department of EE, Comsats Institute of Information Technology Abbottabad \\ Pakistan. \\ Email:sikandarkhan@ciit.net.pk \\ ${ }^{2}$ Comsats Institute of Information Technology \\ Department of EE, Comsats Institute of Information Technology Sahiwal Pakistan. \\ Email: saeeda@ciitsahiwal.edu.pk \\ ${ }^{3}$ University of Engineering and Technology \\ Department of Telecommunication Engineering Department Taxila Pakistan. \\ Email: adeel.akram@uettaxila.edu.pk
}

\begin{abstract}
Wi-Fi performs a figurative role for interior surroundings in localization lacking of any supplementary procedure or tools by means of IEEE 802.11principles. User's site is planned on the foundation of Received Signal Strength Indicator (RSSI) commencing of Access Points (AP's) contained by coverage vicinity through using Revisiting Hata Okumara Formula model and method adopted is Trilateration. Tentative outcomes concluded that results are improved approximately concerning about $1.1 \mathrm{~m}$ referenced to preceding work using the similar practice. Statistical figures shows upgrading of outcome in efficiency and being exact enough to situate user surrounded by $1 \mathrm{~m}$ or lesser in an enclosed atmosphere.
\end{abstract}

Keywords: Wireless Fidelity, Signals Strength, Access Points

\section{Introduction}

Wi-Fi 802.11g is a standard that offers an efficient data rate up to 54Mbps that operates at $2.4 \mathrm{GHz}$ having a toward the rear compatibility with the $802.11 \mathrm{~b}$ procedures. Location of the movable user could be calculated by means of the Received Signal Strength Indicator (RSSI) from the Access Points (APs) or the objective. The major and minor milestone to be achieved all over the research are, the primary objective of this study is to adopt a method to provide a flexible as well as scalable result that will supervise and investigate the position of the things in an indoor environment with high accuracy.

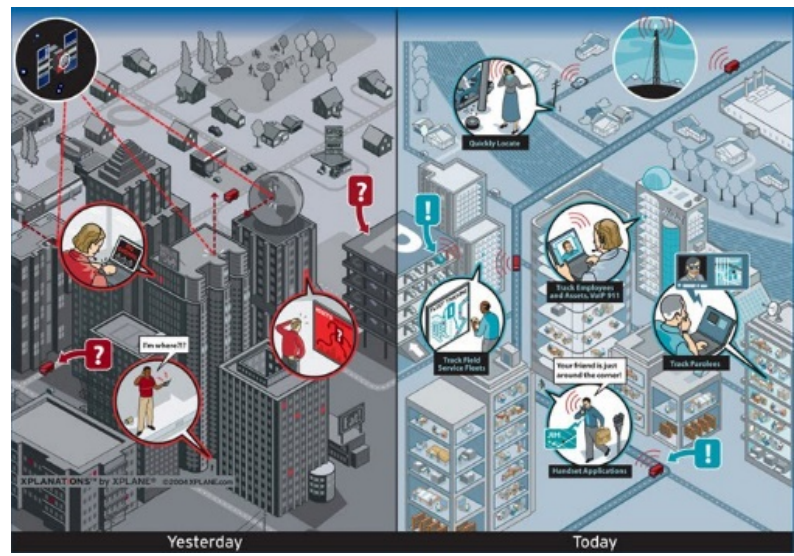

Fig. 1 Structure of Indoor positioning User Cases

(Source: http://www.gpsworld.com/wireless localization/indoor-positioning) 
South American Journal of Academic Research

Special Issue May 2016

\section{Related Work}

In the preceding decade or so, wireless local area networks (WLANs) gained a lot of recognition. "Wi-Fi Alliance products that are based on IEEE standards (802.11 a, b, g, n)" .Indoor environment deals with a problem of localizing the objects. Wireless sensor networks are use to examine the physical, natural or environmental circumstances such as temperature, sound, humidity, vibration, pressure, volcano areas, Navigation, forest fire places, and humidity so on these networks are named as emergency sensor networks (ESN) [1]. Wireless Localization technology has a promising prospect impact to serve in an indoor environment [2]. This application include real time tracking things, objects, emergency based detections, incident monitoring, distant health care, telemetry system.

GPS is a well-liked technology in considering outdoor environment [3] GPS provide satellites based positioning at current which is extensively used in the globe. GPS restrictions occur in an indoor environment as objects or targets cannot be detected in this scenario. A person spends most of the moment in indoor environments; indoor tracking is necessary to fulfill the requirement for tracking in an indoor localization technology that has been deployed [4]. Complication for indoor environments include some of the challenges i.e. NLOS (Non Line Of Sight), absorption, reflection, scattering, fading, refraction, multipath effect, attenuation, noise interference and disturbances like walls, concrete, cupboards, glass and human beings too. But these influences result in the weaknesses for the signals, these effects can't be abandoned. Several review papers are for indoor localization environments [5][6][7].

A wireless set of connections consists of many types (GSM, WLAN, Zigbee, Wi-Fi, UMTS, EDGE, LTE and WiMAX) [8]. Wi-Fi technology is useful in indoor environment for the reason that as for considering its ease of access and charge which is very little. Accurateness and Precision are the essential main factors in an indoor localization, limited signals id degradation in accuracy of positioning [9][10]. Indoor positioning finding is attained by using Wi-Fi signal strengths (SS), and formulae for localizing in user's position. Wi-Fi signals are based on radio waves where travelling of signals are fully dependent upon its frequency [11]. Signals are transmitted through Access Point's (APs) in omni-direction regarding their specific signal strengths. Wireless router can cover an average region of about 35 meters i.e. (125 feet).

Indoor environment face a lot of troubles due to which limitation in the power of the signal occur owing to path loss since it become weaker as for as distance is increased from the origin[12]. Loss is associated to the dimension of material, focusing on its width; attenuation cause due to glass is superior to brick walls [13].These factors have a significant impact particularly by means of the methods to determine distances by calculating the signal strengths [14].By experiment it is accomplished that with the occurrence of users the signal strength is distorted [15]. The signal strength is therefore weakening owed to the humans in an environment. The radiations are up to some extent absorbed as human beings contain water in their bodies in addition to this attenuation occurring in the signal strength. Position of a mobile tool with signal strength plot relates measurements with a SS plot. Two approaches are there for measurement corresponding either Deterministic [16] or else by Probabilistic [17] Localization is a main feature in deploying Wireless Local Area Network (WLAN) [18].

\section{Methodology}

Localization is achieved in indoor environment by means of the already accessible infrastructure within a campus or building. This experiment consists of three APs. The Access Points are situated as more area must be enclosed. The routers are initially configured by 802.11 Wi-Fi standards. During configuring the routers it must be notice that for each AP the guide must be special so that interference may not occur and the RSSI provided by AP must be exact. Most important of alla client server application is programmed in C sharp Language. The cause behind developing this appliance is that we can't find the RSSI values of the user at our server. This value is only accessible at the user end or client system. 


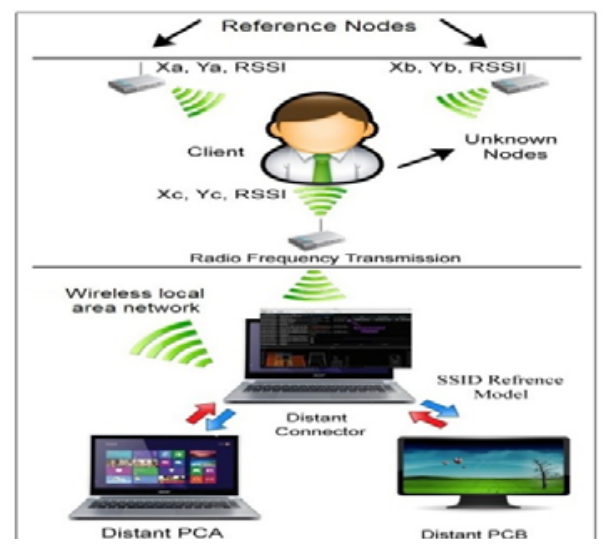

Fig. 2 System Model

Client side consists of wireless networks names within which all of the available and working Access Points are revealed in the chart with reference to each AP, signal strengths for each Access point is also determined. It will present a page which includes names of all the existing Access point; however in this testing we will require just three Access points, so there is a building block to filter the networks that is our ideal motive. The user must be associated with a primary node Access point. The RSSI values of the primary node Access Point, inferior node AP1 and inferior node AP2 is presented. At this moment these values of Received Signal Strength Identification must be available on our main server to locate out the distance estimation of the unknown user or target from each of the nearby Access Points. The function of the server is that it starts monitoring the information that what is send by the user side which includes all of the RSSI values about the desired Access Points and their individual received power which are taken in $\mathrm{dBm}$.

After these fundamental values we are keen into the influences of main obstacles which are from glass, woods, concrete, walls, doors, materials, partitions etc. Generally in such a situation path loss exponent is considered 4 but considering it for free space its value is taken 2 , but in our environment there are huge obstacles such as racks, curtains, chairs, computers, tables, sheets, glass, looking into all these compulsory obstacles the value for " $n$ " is taken flanked by $(3.5-4.0)$. Standard deviation (Xa) have values of (2 -4) respectively, however as signal power varies its value so it is set at (3-5) and value of 20 is considered when there are massive obstacles in the environment. The scaled for $\mathrm{dBm}$ factor is taken to be 100 for which the maximum RSSI is used as 100 . But as a matter of fact it is not exactly 100 but it is due to the internal system software of the computer or Laptop because it shows us its upper limits which is not an accurate value. Considering empirical constant which is equal to -15 in this case. As in 802.11 standard frequency is $2.4 \mathrm{GHz}$ for " $\mathrm{n}$ " standard and the value of wavelength ( ) by calculation is equal to 0.13 .

The most significant formula for finding the distance estimation is Revisiting HataOkumara Model (RHOM) in which the logarithmic distance block is the simplest one [19].

For the values of RHOM Cisco provide us relatively accurate outcome but they are specifically planned for an environment which is ideal and without influences considering obstacles. Distance is calculated by the formula as shown below.

$$
\left.D=\frac{1}{10}\left(P_{T X}-P_{R X}+G_{T X}+G_{R X}-X_{a}+20 \log \lambda-20 \log 4 \pi\right)\right)
$$

Through putting the intended values in the above formula user's distance is calculated from each AP.Distance for each APs is shown in lengths that is in meters and respectively in feet's. Outcomes of the distances are calculated from each single one of the Access Points that are shown on a specific plot. The plot is sketched for anAcademia campus that includes rooms, lecture halls, blocks, offices, equipments, library, laboratories and stairs so there is a massive 
South American Journal of Academic Research

Special Issue May 2016

influence of obstacles. Essentially there are two procedures as a result of which the position of theuser or target can be achieved i.e. Triangulation and Triletaration. But in this experiment the method adopted is Trilateration.

However in Trilateration we work withdistances referring a type of proportions that is used basically for calculating the position of a specific task by using geometry of circles, squares, spheres or triangles [20][21][22][23].

\section{Experimental study}

Experimental setup basically consists of three Access Points (APs), two laptops or computers. Study is done by Access points which are placed in an area depending upon its coverage area for Wi-Fi in an indoor location which is approximately 35 meters or 125 feet's. APs are positioned at different spaces such that Signal Strength must be greater when received by user equipment. As we have two types of directivity of radiations omnidirectional and directional but taking omnidirectional case signals are lost up to a huge extent as we do not require signals in all directions, so it can't be used for this particular case. To make Signal strength increase we can use of directional antenna with the Access Point for greater intensity or radiations in a specific area.

In our practical phase and deployment scenario, the primary one is Primary AP "sikandar 1" similarly the second is Secondary AP1 "sikandar2" and the third is Secondary AP2 "sikandar 3" that are filtered at the client area. Designed for each AP its Received Signal Strength Identification values are shown in table and its respective Received Power (PRX) values. Determination of the distance is the major part of this experiment. By inserting the value of (PRX) which is found from each Access Point, putting its value in RHOM model D1, $\mathrm{D} 2$, and D3 is calculated. Subsequent to distance estimation Trilateration method is used to find out location of the unknown user.

After finding the distancse the values of " $i$ " and " $j$ " are calculated which is found by their specific formula such as,

$$
i=x_{3}-x_{1}
$$

And

$$
j=y_{3}-y_{2}
$$

When the calculated values of "I" and "J" are determined the last and important step is to calculate the coordinates of the target or user on the map, which basically means calculating its " $x$ " and " $y$ " values. To find out " $x$ " and " $y$ " coordinates following formulae are used.

For $\mathrm{x}$

$$
x=\frac{r_{1}^{2}-r_{2}^{2}+d^{2}}{2 d}
$$

Also for $\mathrm{y}$

$$
y=\frac{r_{1}^{2}-r_{3}^{2}-x^{2}+(x-i)^{2}+j^{2}}{2 j}
$$

Where:

"d" is the Distance between Primary Access Point and Secondary Access Point.

" $r 1$ " is the distance of Primary Access Point that is D1.

"r2" is the distance of Secondary Access Point 1 that is D2.

"r3" is the distance of Secondary Access Point 2 that is D3.

Finally the coordinates of the unknown user or target on the map are resulting its radius are sketched from each Access Point (AP). Unknown user has a location where all the three radii 
of circles overlap or cut each other. User position is at a single spot or point so there must be just a single point at which all the radii of circles will intersect each other that is the common point or location amongst all circles from the three Access Point's.

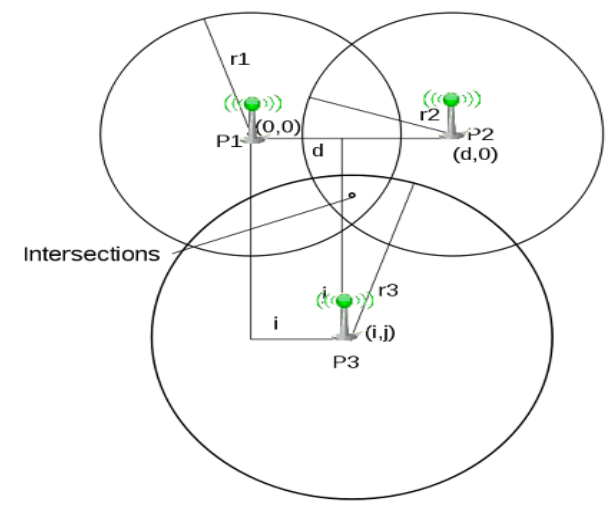

Fig. 3 Trilateration technique for distance estimation

\section{Experimental results}

Distances are determined by (RHOM) formula. The results are founded on the basis of Received Rower (PRX) values which are given below. Total numbers of experiments conducted are 24 some of their calculated values are shown in the table below:

\begin{tabular}{|c|c|c|c|c|}
\hline S.No & $\begin{array}{l}\text { Received Power } \\
\text { from AP's }\end{array}$ & $\begin{array}{c}\text { Distance } \\
\text { from AP's }\end{array}$ & $\begin{array}{c}\text { Map } \\
\text { Location }\end{array}$ & $\begin{array}{l}\text { Localization } \\
\text { (Accuracy) }\end{array}$ \\
\hline 1 & $\begin{array}{l}P_{\mathrm{rx} 1}=-12 \mathrm{dBm} \\
P_{\mathrm{rx} 2}=-49 \mathrm{dBm} \\
P_{\mathrm{rx} 3}=-52 \mathrm{dBm}\end{array}$ & $\begin{aligned} \mathrm{D}_{1} & =1.091 \mathrm{~m} \\
\mathrm{D}_{2} & =14.523 \mathrm{~m} \\
\mathrm{D}_{3} & =14.633 \mathrm{~m}\end{aligned}$ & $\begin{array}{l}X=343 \\
Y=221\end{array}$ & $0.78 \mathrm{~m}$ \\
\hline 2 & $\begin{array}{l}P_{\mathrm{rx} 1}=-9 \mathrm{dBm} \\
\mathrm{P}_{\mathrm{rx} 2}=-47 \mathrm{dBm} \\
\mathrm{P}_{\mathrm{rx} 3}=-53 \mathrm{dBm}\end{array}$ & $\begin{aligned} \mathrm{D}_{1} & =0.354 \mathrm{~m} \\
\mathrm{D}_{2} & =13.043 \mathrm{~m} \\
\mathrm{D}_{3} & =17.843 \mathrm{~m}\end{aligned}$ & $\begin{array}{l}X=356 \\
Y=190\end{array}$ & $0.82 \mathrm{~m}$ \\
\hline 3 & $\begin{array}{l}P_{\mathrm{rx} 1}=-38 \mathrm{dBm} \\
\mathrm{P}_{\mathrm{rx} 2}=-18 \mathrm{dBm} \\
\mathrm{P}_{\mathrm{rx} 3}=-31 \mathrm{dBm}\end{array}$ & $\begin{aligned} \mathrm{D}_{1} & =11.713 \mathrm{~m} \\
\mathrm{D}_{2} & =5.803 \mathrm{~m} \\
\mathrm{D}_{3} & =9.133 \mathrm{~m}\end{aligned}$ & $\begin{array}{l}X=380 \\
Y=270\end{array}$ & $0.77 \mathrm{~m}$ \\
\hline 4 & $\begin{array}{l}P_{\mathrm{rx} 1}=-13 \mathrm{dBm} \\
\mathrm{P}_{\mathrm{rx} 2}=-43 \mathrm{dBm} \\
\mathrm{P}_{\mathrm{rx} 3}=-52 \mathrm{Dbm}\end{array}$ & $\begin{aligned} \mathrm{D}_{1} & =4.143 \mathrm{~m} \\
\mathrm{D}_{2} & =12.943 \mathrm{~m} \\
\mathrm{D}_{3} & =17.263 \mathrm{~m}\end{aligned}$ & $\begin{array}{l}X=362 \\
Y=229\end{array}$ & $0.79 \mathrm{~m}$ \\
\hline 5 & $\begin{array}{l}P_{\mathrm{rx} 1}=-15 \mathrm{dBm} \\
\mathrm{P}_{\mathrm{rx} 2}=-48 \mathrm{dBm} \\
\mathrm{P}_{\mathrm{rx} 3}=-55 \mathrm{Dbm}\end{array}$ & $\begin{aligned} \mathrm{D}_{1} & =4.073 \mathrm{~m} \\
\mathrm{D}_{2} & =12.73 \mathrm{~m} \\
\mathrm{D}_{3} & =17.133 \mathrm{~m}\end{aligned}$ & $\begin{array}{l}X=360 \\
Y=226\end{array}$ & $0.72 \mathrm{~m}$ \\
\hline 6 & $\begin{array}{l}P_{\mathrm{rx} 1}=-17 \mathrm{dBm} \\
\mathrm{P}_{\mathrm{rx} 2}=-37 \mathrm{dBm} \\
\mathrm{P}_{\mathrm{rx} 3}=-49 \mathrm{Dbm}\end{array}$ & $\begin{array}{c}\mathrm{D}_{1}=4.15 \mathrm{~m} \\
\mathrm{D}_{2}=13.043 \mathrm{~m} \\
\mathrm{D}_{3}=16.06 \mathrm{~m}\end{array}$ & $\begin{array}{l}X=364 \\
Y=226\end{array}$ & $0.74 \mathrm{~m}$ \\
\hline 7 & $\begin{array}{l}P_{\mathrm{rx} 1}=-16 \mathrm{dBm} \\
\mathrm{P}_{\mathrm{rx} 2}=-49 \mathrm{dBm} \\
\mathrm{P}_{\mathrm{rx} 3}=-58 \mathrm{Dbm}\end{array}$ & $\begin{array}{c}\mathrm{D}_{1}=4.10 \mathrm{~m} \\
\mathrm{D}_{2}=13.011 \mathrm{~m} \\
\mathrm{D}_{3}=18.093 \mathrm{~m}\end{array}$ & $\begin{array}{l}X=355 \\
Y=231\end{array}$ & $0.63 \mathrm{~m}$ \\
\hline
\end{tabular}


South American Journal of Academic Research

Special Issue May 2016

\begin{tabular}{|c|c|c|c|c|}
\hline 8 & $\begin{array}{l}P_{\mathrm{rx} 1}=-18 \mathrm{dBm} \\
\mathrm{P}_{\mathrm{rx} 2}=-48 \mathrm{dBm} \\
\mathrm{P}_{\mathrm{rx} 3}=-52 \mathrm{Dbm}\end{array}$ & $\begin{aligned} \mathrm{D}_{1} & =5.247 \mathrm{~m} \\
\mathrm{D}_{2} & =13.143 \mathrm{~m} \\
\mathrm{D}_{3} & =16.897 \mathrm{~m}\end{aligned}$ & $\begin{array}{l}X=364 \\
Y=221\end{array}$ & $0.86 \mathrm{~m}$ \\
\hline 9 & $\begin{array}{l}\mathrm{P}_{\mathrm{rx} 1}=-12 \mathrm{dBm} \\
\mathrm{P}_{\mathrm{rx} 2}=-45 \mathrm{dBm} \\
\mathrm{P}_{\mathrm{rx} 3}=-55 \mathrm{Dbm}\end{array}$ & $\begin{array}{c}\mathrm{D}_{1}=4.269 \mathrm{~m} \\
\mathrm{D}_{2}=13.643 \mathrm{~m} \\
\mathrm{D}_{3}=17.467 \mathrm{~m}\end{array}$ & $\begin{array}{l}X=363 \\
Y=227\end{array}$ & $0.82 \mathrm{~m}$ \\
\hline 10 & $\begin{array}{l}P_{\mathrm{rx} 1}=-14 \mathrm{dBm} \\
\mathrm{P}_{\mathrm{rx} 2}=-40 \mathrm{dBm} \\
\mathrm{P}_{\mathrm{rx} 3}=-52 \mathrm{Dbm}\end{array}$ & $\begin{aligned} \mathrm{D}_{1} & =4.147 \mathrm{~m} \\
\mathrm{D}_{2} & =11.563 \mathrm{~m} \\
\mathrm{D}_{3} & =16.289 \mathrm{~m}\end{aligned}$ & $\begin{array}{l}X=365 \\
Y=221\end{array}$ & $0.73 \mathrm{~m}$ \\
\hline 11 & $\begin{array}{l}P_{\mathrm{rx} 1}=-17 \mathrm{dBm} \\
\mathrm{P}_{\mathrm{rx} 2}=-52 \mathrm{dBm} \\
\mathrm{P}_{\mathrm{rx} 3}=-61 \mathrm{Dbm}\end{array}$ & $\begin{aligned} \mathrm{D}_{1} & =4.023 \mathrm{~m} \\
\mathrm{D}_{2} & =16.694 \mathrm{~m} \\
\mathrm{D}_{3} & =17.263 \mathrm{~m}\end{aligned}$ & $\begin{array}{l}X=344 \\
Y=210\end{array}$ & $0.77 \mathrm{~m}$ \\
\hline 12 & $\begin{array}{l}P_{r \times 1}=-16 \mathrm{dBm} \\
P_{r \times 2}=-41 \mathrm{dBm} \\
P_{r \times 3}=-59 \mathrm{Dbm}\end{array}$ & $\begin{array}{c}\mathrm{D}_{1}=4.27 \mathrm{~m} \\
\mathrm{D}_{2}=12.894 \mathrm{~m} \\
\mathrm{D}_{3}=17.298 \mathrm{~m}\end{array}$ & $\begin{array}{l}X=335 \\
Y=195\end{array}$ & $0.84 \mathrm{~m}$ \\
\hline 13 & $\begin{array}{l}P_{r \times 1}=-11 \mathrm{dBm} \\
P_{r \times 2}=-45 \mathrm{dBm} \\
P_{\mathrm{rx} 3}=-55 \mathrm{Dbm}\end{array}$ & $\begin{array}{c}\mathrm{D}_{1}=4.03 \mathrm{~m} \\
\mathrm{D}_{2}=12.467 \mathrm{~m} \\
\mathrm{D}_{3}=17.828 \mathrm{~m}\end{array}$ & $\begin{array}{l}X=363 \\
Y=229\end{array}$ & $0.76 \mathrm{~m}$ \\
\hline
\end{tabular}

Fig. 4 Calculated outcomes of Distances and localization in mapping using 3 AP's.

\section{Conclusion}

Wireless localization technology has undergone a substantial improvement in the earlier period decades. Wi-Fi based Positioning structure has an imperative part for improving the performance to track in an inside environment lacking the need of specialize positioning procedure. Locality can be achieved by present devices in an indoor environment. Superior adaptation is able to achieve as we gained the data from additional reference points (APs) for any indoor environment. Localization information points as diversity has a unswerving relation with tracking accurateness for unknown targets. Provisioning to Wireless access along with data communication technologies are swiftly enhancing with instant. In recent years, wireless communication has matured enormously. Users are constantly shifting from wired networks toward wireless in homes and office. Wireless access as well provides the magnificence of mobility that is even further smart for mobile users. In this approach we can get better the competence of these services. Localization for open-air system can be achieved easily by means of using GPS. At the start, it was deployed in favor of military purpose and it has a very high exactness in manipulating its targets.

Limitation occurs as soon as the sky is not clear; detecting objective position become almost impractical. GPS has improved results for outdoor surroundings, for indoor situation some additional technology is adopted. The basic purpose of deploying Wi-Fi is its availability, flexibility, mobility, less time, connectivity at a much lesser cost. Special standards for Wi-Fi structure are developed by IEEE 802 operational group out of which $802.11 \mathrm{~b}$ and $802.11 \mathrm{~g}$ has develop into a standard for industry that work at $11 \mathrm{Mbps}$ and $54 \mathrm{Mbps}$ correspondingly for the frequency band of $2.4 \mathrm{GHz}$ which includes the Industrial, Scientific and Medical (ISM)band presented worldwide devoid of requiring any license.

The planned method adopted is to compute location of an unknown user or target in an indoor setting by using Wi-Fi Signal Strengths (SS) that is IEEE 802.11 standards. Experimental study was performed in a university campus building for an indoor environment where influences of obstacles were enormous. The method adopted here is Trilateration. Precise enough for localizing a user within a range of $1 \mathrm{~m}$ or less. 
Innovative research efforts are required to tackle these kinds of issues in the nearby future.

\section{Acknowledgement}

The authors acknowledge the efforts of Saeeda Usman for providing previous experimental data and perceptive ideas towards promising solutions for enhancing accuracy in our algorithm.

\section{References}

[1] Ambili Thottam Parameswara and Mohammad Iftekhar Husain, "Is RSSI a Reliable Parameter in Sensor Localization Algorithms - An Experimental Study," , USA, 2009.

[2] Da Zhang and Wenhong Zhao, "Localization Technologies for Indoor Human Tracking," in Future Information Technology (FutureTech), 2010, pp. 1- 6.

[3] Binghao Li and Andrew G. Dempster, "On outdoor positioning with Wi-Fi," Journal of Global Positioning Systems, vol. Vol. 7, no. No. 1 :, pp. 18-26, (2008).

[4] Holger Linde, "On Aspects of Indoor Localization," August 2006.

[5] Yanying Gu, Anthony Lo, and Ignas Niemegeers, "A Survey of Indoor Positioning Systems for Wireless Personal Networks," IEEE Communications Surveys \& Tutorials, vol. vol. 11, no. no. 1, pp. 13-32, 2009.

[6] Isaac Amundson and Xenofon D. Koutsoukos, "A Survey on Localization for Mobile Wireless Sensor Networks," MELT, no. LNCS 5801, pp. 235-254, 2009.

[7] Hui Liu, H. Darabi, P. Banerjee, and Jing Liu, "Survey of Wireless Indoor Positioning Techniques and Systems," IEEE Trans. Systems, Man, and Cybernetics, Part C, vol. 37, no. 6, pp. 1067-1080, October 2007.

[8] Crow BP, Widjaja I, kim JG, and Sakai P, "IEEE 802.11 wireless local area networks," IEEE Commun Mag, vol. 35, no. 9, pp. 116-126, 1997.

[9] Stuart Ingram, "UltraWideBand Indoor Positioning: Indoor posi-tioning to match the best satellite navigation performance," no. 2, july 2006.

[10] George Dedes and Andrew G Dempster, "Indoor GPS Positioning: Chal-lenges and Opportunities," Vehicular Technology Conference, 2005. VTC-2005-Fall. 2005 IEEE 62nd, vol. 1, pp. 412- 415, Sept 2005.

[11] Nor Aida Mahiddin, Noaizan Safie, Elissa Nadia, Suhailan Safei, and Engku Fadzli, "INDOOR POSITION DETECTION USING WIFI AND TRILATERATION TECHNIQUE," in The International Conference on Informatics and Applications, Malaysia, (2012), pp. 362-366.

[12] Robin Henniges, "Current approches of Wifi Positioning," SERVICE-CENTRIC NETWORKING, 2012.

[13] John C. Stein, "Indoor Radio WLAN Performance," Palm Bay, Florida, Harris Semiconductor.

[14] Robin Henniges, "Current approches of Wifi Positioning," , TU-Berlin , Germany, 2012.

[15] K. Kaemarungsi and P. Krishnamurthy, "Properties of indoor received signal strength for WLAN location fingerprinting," in Mobile and Ubiquitous Systems: Networking and Services, 2004. MOBIQUITOUS 2004. The First Annual International Conference, USA, Aug. 2004, pp. 14- 23.

[16] Paramvir Bahl and Venkata N. Padmanabhan, "An In-Building RF-based User Location and Tracking System," INFOCOM - IEEE INFOCOM, vol. 2, pp. 775-784, 2000.

[17] R Roos, P. Myllymäki, H. Tirri, P. Misikangas, and J. Sievänen, "A Probabilistic Approach to WLAN User Location Estimation," International Journal of Wireless Information Networks, vol. 9, no. 3, pp. 155-164, July 2002.

[18] Nattapong Swangmuang and Prashant Krishnamurthy, "Location Fingerprint Analyses Toward Efficient Indoor Positioning," Pervasive. Computing and Communications, 2008. PerCom 2008. Sixth Annual IEEE International Conference on, pp. 100- 109, March 2008.

[19] Frédéric EVENNOU and François MARX, "Improving positioning capabilities for indoor environments with WiFi," in LIAISON, France, 2006, pp. 35-42.

[20] http://www.globmaritime.com/technical-articles/marine-navigation/general-concepts/9622trilateration-traverse-and-vertical-surveying.html, 2009, wikipedia search.

[21] http://www.thefreedictionary.com/trilateration, 2003, wikipedia search. 
South American Journal of Academic Research

Special Issue May 2016

[22] http://www.diracdelta.co.uk/science/source/t/r/trilateration/source.html\#.UXvJm6tHI-w,wikipedia search.

[23]http://www.britannica.com/EBchecked/topic/605329/trilateration, 2013, wikipedia search.

[24] Hakan Koyuncu, Hakan Koyuncu, and Shuang Hua Yang, "Comparisons of Indoor PositionEnhancements by Using Mean and KalmanFiltering Techniques," vol. VOLUME 11, no. ISSUE 2, FEBRUARY 2012.

[25] M. Depsey, "Indoor Positioning Systems in Healthcare," Radianse Inc. White Paper, 2003

[26] S. Gezici, "A survey on wireless position estimation," Wireless Personal Communications, vol. 44, no. 3, pp. 263-282, Feb 2008.

[27] Lassabe F, Charlet D, Canalda P, Chatonnay P, and Spies F, "Predictive mobility models based on Kth Markov models," IEEE int conf on pervasive services, pp. 303-306, 2006.

[28] Deblauwe N, "GSM-based positioning: techniques and applications," in $\mathrm{PhD}$ thesis, Vrije Universiteit Brussels, (2008.

[29] Frédéric Evennou, "Advanced techniques and technologies for indoor mobile positioning," Université Joseph-Fourier - Grenoble, 2007.

[30] sBarry McLarnon, "A workshop given at the 1997 TAPR/ARRL Digitial Communications Conference," Ottawa, VHF/UHF/Microwave Radio Propagation: A Primer for Digital Experimenters 1997.

[31] Ambili Thottam Parameswaran, Mohammad Iftekhar Husain, and Shambhu Upadhyaya, "Is RSSI a Reliable Parameter in Sensor Localization Algorithms - An Experimental Study," Instrumentation and Measurement Technology Conference (I2MTC), 2012 IEEE International, pp. 935- 940 , 2012.

[32] M. Cypriani, F. Lassabe, P. Canalda, and F. Spies, "Wi-Fi-based indoor positioning: Basic techniques, hybrid algorithms and open software platform," Indoor Positioning and Indoor Navigation (IPIN), 2010 International Conference on, pp. 1- 10, Sept 2010.

[33] Paramvir Bahl and Venkata N. Padmanabhan, "Enhancements to the RADAR User Location and Tracking System," Anand Balachandran , California , February 2000.

[34] J. M. Keenan and A. J. Motley, "Radio coverage in buildings," British Telecom Technology Journal, vol. 8, no. 1, pp. 19-24, June 1990

[35] A. Smailagic and D. Kogan, "Location sensing and privacy in a context-aware computing environment," Wireless Communications, IEEE, vol. 9, no. 5 , pp. 10- 17, Oct. 2002.

[36] Mauro Brunato and Csaba Kiss Kall'o, "Transparent Location Fingerprinting," in Proceedings of Med-Hoc-Net, ITALY, Sep. 2002.

[37] O. Baala and A. Caminada, "WLAN-based Indoor Positioning System: experimental results for stationary and tracking MS," IEEE International Conference on Communication Technology (ICCT’06), pp. 1-4., Nov 2006.

[38] Paramvir Bahl, Padmanabhan N. Venkata, and Anand Balachandran, "Enhancements to the RADAR User Location and Tracking System," Microsoft Research 2000.

[39] G. D. Forney, "The viterbi algorithm," Proceedings of the IEEE, vol. 61, no. 3 , pp. 268 - 278, March 1973.

[40] Roy Want, Andy Hopper, Veronica Falcão, and Jonathan Gibbons, "The Active Badge Location System," in ACM Transactions on Information Systems, vol. 40, Cambridge, England, Jan. 1992., pp. 91- 102 